\title{
Energy and Environmental Impacts of Urban Buses and Passenger Cars-Comparative Analysis of Sensitivity to Driving Conditions
}

\author{
Leonid Tartakovsky ${ }^{1}$, Marcel Gutman $^{1}$, Doron Popescu ${ }^{1} \&$ Michael Shapiro ${ }^{1}$ \\ ${ }^{1}$ Faculty of Mechanical Engineering, Technion-Israel Institute of Technology, Haifa, Israel \\ Correspondence: Leonid Tartakovsky, Faculty of Mechanical Engineering, Technion-Israel Institute of \\ Technology, Haifa 32000, Israel. Tel: 972-4-829-2077. E-mail: tartak@technion.ac.il
}

Received: April 18, 2013 Accepted: May 20, 2013 Online Published: June 19, 2013

doi:10.5539/ep.v2n3p81 URL: http://dx.doi.org/10.5539/ep.v2n3p81

\begin{abstract}
A methodology is suggested for a comparative analysis of energy and environmental impacts of various urban transport modes. A total emission indicator is used as a tool for integral assessment of vehicle emissions. An environmental impact factor is suggested in order to compare between the various transport modes that use different energy sources. Vehicle occupancy values, yielding equality of the specific environmental impact factors and specific energy consumption of the compared transport modes are used for the analysis purposes. This methodology is applied for a comparison between the buses and the passenger cars at various levels of service, road gradients and urban road types. The comparison results reveal that the environmental impact of the bus for driving at an urban access road falls below the one of the passenger car when the bus occupancy is 14-18 persons. Urban buses turn out to be energetically beneficial over passenger cars at occupancy values substantially lower compared with those providing a similar environmental impact.
\end{abstract}

Keywords: energy and environmental impacts, total emission indicator, environmental impact factor, urban bus, passenger car

\section{Introduction}

Urban air pollution induced by road vehicles has become a deep concern all over the world. Vehicle emissions that include particles and toxic gases adversely affect cardio-vascular, respiratory and immune systems, thus by increasing the risk of stroke and cancer development (Pope \& Dockery, 2006; Sram et al., 2011). Nano-particles penetrate through the blood cells into the human brain, liver etc. with concomitant negative health effects (Wang et al., 2012).

Various studies ensuring urban sustainable mobility are being explored worldwide to resolve problems of land use, traffic congestion, energy consumption and air pollution caused by road transportation. The possible solutions to circumvent this is to promote public transport as an alternative to individual transportation; tax incentives to bring on the roads to become environmentally friendly for vehicles implementation of Intelligent Transportation Systems (ITS), such as road tolling, congestion pricing, cybernetic transportation, etc.; sustainable urban planning; technological advancements aimed at a reduction of vehicle energy and environmental impacts(Silva et al., 2007; Parent, 2007; Radovic, 2009). Typical examples of such a progress include: engine downsizing and shut-off during idling, developing more efficient vehicle propulsion systems (plug-in hybrids, fuel cells, battery-electric vehicles, etc.), increasing availability of alternative fuels (Ahman, 2001; Dincer et al., 2010; Tartakovsky et al., 2013).

Public transportation in cities can be an effective tool for mobility improvement, traffic congestion reduction and mitigation of urban air pollution. Energy and environmental impacts of public transport depend on the type of vehicles used, driving pattern, road conditions, passengers load and other factors. These impacts should be carefully assessed and compared with those of other transportation modes, first of all-the individual transportation fleet. If the compared transportation modes use different energy carriers, the primary energy consumption and emissions are normally used as a basis for the comparison-well-to-wheel approach (Ahman, 2001).

Emissions from buses or passenger cars of various technologies and at different driving conditions are described quite thoroughly in the literature. Most of these studies are focused on a comparison of a few specific motor 
vehicles at some type of driving conditions. Such a comparison is very important because it provides specific and detailed information on the benefits and drawbacks of the studied vehicle types in the considered usage conditions. Nylund et al. $(2004,2007)$ compared emissions from several preselected diesel and natural gas buses of the emission certification ranged from Euro 3 to the enhanced environmentally friendly vehicle. Fox and Eweka (2009) investigated the performance of hybrid buses under a variety of operating conditions and duty cycles. De Vlieger et al. (2000) studied the influence of driving behavior and traffic conditions on fuel consumption and emissions of nine passenger cars. Tsang et al. (2011) examined the effects of road gradient and traffic conditions on the emissions and fuel consumption of a Euro 4 gasoline car. No comparison has been reported between the energy and the environmental impacts of different urban transportation modes in these works. Information on the emissions comparison between urban buses and passenger cars is quite limited and mainly focused on carbon dioxide emissions (Bradley \& Associates, 2007). Lenaers and De Vlieger (1997) performed on-board measurements of $\mathrm{CO}, \mathrm{HC}$ and $\mathrm{NO}_{\mathrm{x}}$ emissions from six gasoline-driven cars and 5 diesel urban buses on regular city lines. Their research performed in 1997 dealt with vehicles of Euro 0 to Euro 2 technology generations. Silva et al. (2007) investigated the effects of vehicle occupancy on specific fuel consumption and emissions (per person $\cdot \mathrm{km}$ ) for two different driving patterns of low and congested traffic. Two models of diesel urban buses and two models (diesel- and gasoline-driven) of light-duty vehicles were considered. The comparison was performed separately for each pollutant type $\left(\mathrm{CO}_{2}, \mathrm{CO}, \mathrm{HC}, \mathrm{NO}_{\mathrm{x}}\right.$, and $\left.\mathrm{PM}\right)$. The results vary significantly for different pollutants, which makes it difficult to compare between the various transportation modes.

Most of the published works dealt with a comparison of emissions only (Dincer et al., 2010; Granovskii et al., 2006). If road transportation modes based on electric and motor vehicles are to be compared, their environmental impact depends not only on the emissions level, but also on the number of people exposed to the polluted air and therefore subjected to health damage. This requires a development of an overall comparison approach. To resolve this problem we suggest a methodology for comparative analysis of energy and environmental impacts of various urban transport modes. It is based on a total emission indicator as a tool for integral assessment of vehicle emissions. An environmental impact factor is suggested in order to compare between transport modes using different energy sources. The methodology is applied for a comparison of the fleet averaged impacts of buses and passenger cars at various levels of service, road gradients and urban road types. The analysis uses the real world data collected for vehicle fleet composition.

\section{Method}

\subsection{Calculation of Fleet Averaged Emissions and Energy Consumption}

Fleet averaged emission factors and energy consumption of various road transport modes can be calculated by using one of the validated complex Road Emission Models, such as: ARTEMIS, COPERT and others. If electric vehicles (EVs) are presented in the fleet, an appropriate calculation model should be used. Emissions produced due to EVs operation largely depend on technology of electricity generation (Dincer et al., 2010). Fuel mix used for electricity production varies in composition depending on a country or region considered. In our work for the calculation of energy consumption and emission factors of motor vehicles we use the ARTEMIS model (André et al., 2009). The model allows a prediction of emissions and energy consumption for each vehicle and fuel type, technology generation, engine volume (for passenger cars) and driving cycle. It relies on the detailed classification of the vehicles into several categories (cars, buses, etc.). Vehicle categories are further divided into segments according to technology, fuel type and size. For example, buses of standard-, midi- and articulated-configuration may be considered. Passenger cars (PCs) are classified by fuel type, engine size, etc. (Andre \& Rapone, 2009). The segments are broken down by the emission concepts (pre-Euro, Euro1 to 5 plus several other cases). This model is based on the largest in Europe data base containing experimentally measured emission factors. It consists of: emission data set including all the emission data and functions needed for the computation of different emissions, a fleet module enabling a calculation of the detailed fleet composition, an emission factor processor enabling a computation of all the relevant emissions factors, a traffic data set module combining traffic scenarios with applications and an emission computation module providing the total emissions for a given case study. The ARTEMIS model is accepted Europe-wide for the assessment of real-world emissions by various transportation modes. A detailed description of the ARTEMIS model can be found in the work of André et al. (2009).

\subsection{Vehicle Fleet Data}

Information on the fleet composition of the considered transportation mode can be collected from the vehicle operators or published statistical sources. The data on average number of cold starts by various vehicle types is 
usually less accessible. For an urban bus this data was obtained from the bus operators. There are two cold starts per day in average. The number of PC cold starts was assessed with the aid of a questionnaire distributed among 160 drivers. The cars in the sample were selected to represent the local PC fleet composition. A distribution of PC cold starts derived on the basis of the drivers' survey is shown in Figure 1. The mean number of PC cold starts that was used in simulations is 4.7 per day.

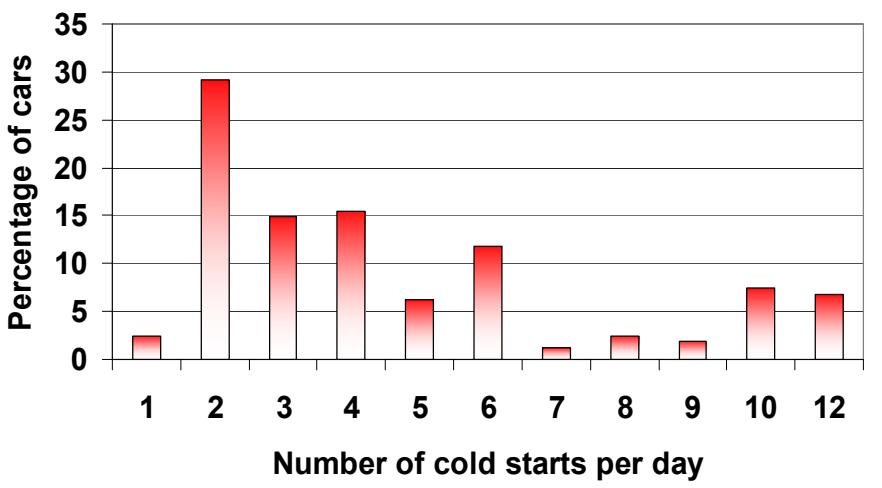

Figure 1. Distribution of PC cold starts

\subsection{Environmental Impact Assessment}

\subsubsection{Total Emission Indicator}

The values of weighted fleet-average emissions by each considered transportation mode should be further processed, to provide a total emission indicator (TEI). The latter is a useful tool for an integral quantitative assessment of vehicle emissions and also for a comparison between different transportation modes. For each vehicle type $T E I$ is defined as the sum of normalized emission values of different pollutants:

$$
T E I=c_{c o r} \sum\left(E M_{i} / T L V_{i}\right)(\mathrm{g} / \mathrm{km})
$$

where: $E M_{i}$-the emission of pollutant $i(\mathrm{~g} / \mathrm{km}) ; T L V_{i}$-threshold limit value for pollutant $i,\left(\mathrm{mg} / \mathrm{m}^{3}\right) ; c_{c o r}$ -dimension correction coefficient $\left(c_{c o r}=1 \mathrm{mg} / \mathrm{m}^{3}\right)$. The $T L V_{i}$ values were taken from the list of Threshold Limit Values and Biological Exposure Indices of the American Conference of Governmental Industrial Hygienists (2010). Some relevant values of $T L V_{i}$ are presented in Table 1.

Table 1. Threshold limit values for selected pollutants (American Conference of Governmental Industrial Hygienists, 2010)

\begin{tabular}{ll}
\hline Pollutant & $T L V_{i}\left(\mathrm{mg} / \mathrm{m}^{3}\right)$ \\
\hline Nitrogen dioxide $\mathrm{NO}_{2}$ (for normalization of $\mathrm{NO}_{\mathrm{x}}$ emissions) & 5.6 \\
Carbon monoxide $\mathrm{CO}$ & 28.5 \\
1,3-Butadiene (for normalization of $\mathrm{HC}$ emissions) & 4 \\
Particulate matter PM2.5 (for normalization of PM emissions) & 3 \\
\hline
\end{tabular}

\subsubsection{Environmental Impact Factor}

The environmental impact of a road transportation mode is a function not only of the emissions level, but also of the number of people that are exposed to the polluted air and therefore exposed to health damage. Thus,major differences are possible between electric vehicles and motor vehicles. To account for this fact, we propose to introduce an environmental impact factor $(E I F)$ to allow a comparison between different transportation modes. The dimensionless $E I F$ value is calculated as:

$$
E I F=T E I \cdot D_{S}
$$

where $D_{s}$ is the receptor density in the site of consideration. Receptor density is calculated as the population per 
$\mathrm{km}^{2}$ of the site area. Since it is usually impossible to distinct between various pollution sources that were involved in the additional electricity production due to electric vehicle activity, the uniform background approach was suggested by Curtiss and Rabl (1996). This approach is applied to calculate EIF values for EVs based transportation modes. Had the world been homogeneous, the receptor density would have been uniform $D_{u}$ The receptor density $D_{s}$ depends on the site. The relative receptor density $f$ can be defined as:

$$
f=D_{s} / D_{u}
$$

The dependence of $E I F$ on $f$ can be used to analyze the environmental impact of different transportation modes.

\subsubsection{Environmental Impact Equality Value}

We will further aim at characterizing the environmental impact of a vehicle group per person moved. Towards this goal for each vehicle group we define the specific environmental impact factor $(S E I F)$ calculated as:

$$
S E I F=E I F / \text { Vehicle Occupancy }
$$

Environmental impacts of different transportation modes, if they emit hazardous pollutants at the same site with the same receptor density, can be determined by the level of their emissions. In this case the specific total emission indicator (STEI) calculated per person $\mathrm{km}$ will be enough for comparison purposes:

$$
\text { STEI }=\text { TEI } / \text { Vehicle Occupancy }(\mathrm{g} / \mathrm{person} \cdot \mathrm{km})
$$

SEIF or STEI values can be used to compare the environmental impacts of the considered transportation modes. For example, if urban buses are compared with passenger cars, we can calculate the bus occupancy (BO) for any given PC occupancy, yielding equality of the Bus and PC SEIF or STEI. We will call this quantity SEIF (STEI) equality $B O$. In the considered example, for any specified PC occupancy STEI equality BO represents the minimal number of bus passengers required to ensure that the buses STEI remains below STEI of the passenger cars.

\subsection{Energy Impact Assessment}

Similar to $S T E I$ equality $B O$, bus occupancy values that providethe equality of specific fuel consumption ( $S F C$ ) between a bus and PC (called hereafter $S F C$ equality $B O$ ) can be computed and used for energy impact comparison. $S F C$ is calculated as:

$$
S F C=F C / \text { Vehicle Occupancy }(\mathrm{g} / \text { person } \cdot \mathrm{km})
$$

where $F C$ is vehicle fuel consumption in $(\mathrm{g} / \mathrm{km})$.

If the compared transportation modes include vehicles using different energy carriers, the primary energy consumption will be used as a basis for the comparison. A vehicle occupancy value that provides the equality of the specific energy consumption should be computed and used in this case.

\subsection{Considered Case: Buses and Passenger Cars}

The methodology described in sections 2.1-2.4 was applied for the case of urban buses and passenger cars comparison at various levels of service, road gradients and urban road types. In all calculations we presumed the use of diesel fuel and gasoline with sulfur content lower than $10 \mathrm{ppm}$ that meets the European Directive 2009/30/EC. Calculations were carried out for different values of the bus or car passenger occupancy. Weighted fleet-average values of emission factors were calculated for buses and PCs using the fleet composition data presented in Tables 2 and 3, respectively.

Table 2. Composition of the considered urban buses fleet (\%)

\begin{tabular}{lllllllll}
\hline \multirow{2}{*}{ Bus type } & \multicolumn{9}{c}{ Technology generation } & \multirow{2}{*}{ Total } \\
\cline { 2 - 6 } & Euro 0 & Euro 1 & Euro 2 & Euro 3 & Euro 4 & Euro 5 & percentage \\
\hline Articulated & 4.2 & 0.9 & 0.8 & 9.7 & 5.4 & 0 & 21 \\
Standard & 0.1 & 6.8 & 21 & 35 & 13 & 2.1 & 78 \\
Midi & 0 & 0 & 1 & 0 & 0 & 0 & 1 \\
\hline
\end{tabular}

A comparison between energy and environmental impacts of buses and PCs was performed for different traffic and road conditions. The following levels of service, commonly considered in the traffic situation scheme, were analyzed (André et al., 2006): 
- Free flow-free flowing conditions with low and steady traffic flow. Constant and quite high speed. On roads with a speed limit of $50 \mathrm{~km} / \mathrm{h}$ the speed is $45-60 \mathrm{~km} / \mathrm{h}$.

- Stop \& Go-heavily congested flow, stop and go or gridlock. Variable and low speed and stops typical for city center driving with traffic jams. Indicative speed $5-15 \mathrm{~km} / \mathrm{h}$ on roads with a speed limit of 50 $\mathrm{km} / \mathrm{h}$.

At each level of service calculations were performed for the average road gradients of $0,2,4$ and $6 \%$. The road types considered in these simulations were the urban access road with a speed limit of $50 \mathrm{~km} / \mathrm{h}$ and the urban distributor type road with a speed limit of $80 \mathrm{~km} / \mathrm{h}$. A detailed description of these road types appears in (André et al., 2006).

Table 3. Composition of the considered PC fleet (\%)

\begin{tabular}{llllllll}
\hline $\begin{array}{l}\text { PC by engine } \\
\text { volume (l) \& fuel } \\
\text { type }\end{array}$ & Euro 0 & Euro 1 & Euro 2 & Euro 3 & Euro 4 & Euro 5 & $\begin{array}{c}\text { Total } \\
\text { percentage }\end{array}$ \\
\cline { 2 - 6 }$<1.4$, gasoline & 1.3 & 0.8 & 1.7 & 2.4 & 2.1 & 0.9 & 9.2 \\
$<1.4$, diesel & 0 & 0 & 0 & 0 & 0 & 0 & 0 \\
$1.4-2.0$, gasoline & 12.2 & 6.8 & 14.8 & 21.3 & 18.5 & 8.2 & 81.8 \\
$1.4-2.0$, diesel & 0 & 0.1 & 0.6 & 0.8 & 0.8 & 0.2 & 2.5 \\
$>2.0$, gasoline & 0.9 & 0.5 & 1.2 & 1.7 & 1.5 & 0.7 & 6.5 \\
$>2.0$, diesel & 0 & 0 & 0 & 0 & 0 & 0 & 0 \\
\hline
\end{tabular}

\section{Results and Discussion}

\subsection{Comparison of Environmental Impacts}

Figure2 presents the dependence of STEI equality $B O$ values on PC occupancy for urban access roads. At the "free flow" conditions and average PC occupancy of 1.2 (typical European PC occupancy for commuting trips to/from work) the fleet averaged emissions by an urban bus, expressed in specific TEI values, become lower compared to a passenger car, if the bus passenger load exceeds 18. For the "stop \& go" traffic and the same PC occupancy of 1.2, an urban bus is starting to be environmentally beneficial, if its passenger occupancy is higher than 14. In other words, (for any given PC occupancy) the STEI equality BO value becomes lower, if the traffic is more congested. Therefore, the growth of emissions per passenger with an increasing traffic load is lower for buses than for passenger cars. One can see that with respect to the increasing traffic load buses are a more environmentally beneficial vehicle group than PC.

One of the probable reasons of this trend is a difference between the diesel and SI engine's mechanical efficiencies due to throttling losses. This difference is higher at lower loads typical for the "stop \& go" traffic. In the case considered in this paper the fleet of PCs almost entirely consists of cars with spark ignition engines (see Table 3) as opposed to buses equipped by diesel engines that have no throttle. The difference between STEI equality $B O$ values for the free flow and "stop \& go" levels of service is growing with an increase in PC occupancy. The results obtained for the average road gradient of $6 \%$ are similar and indicate the same tendency. 


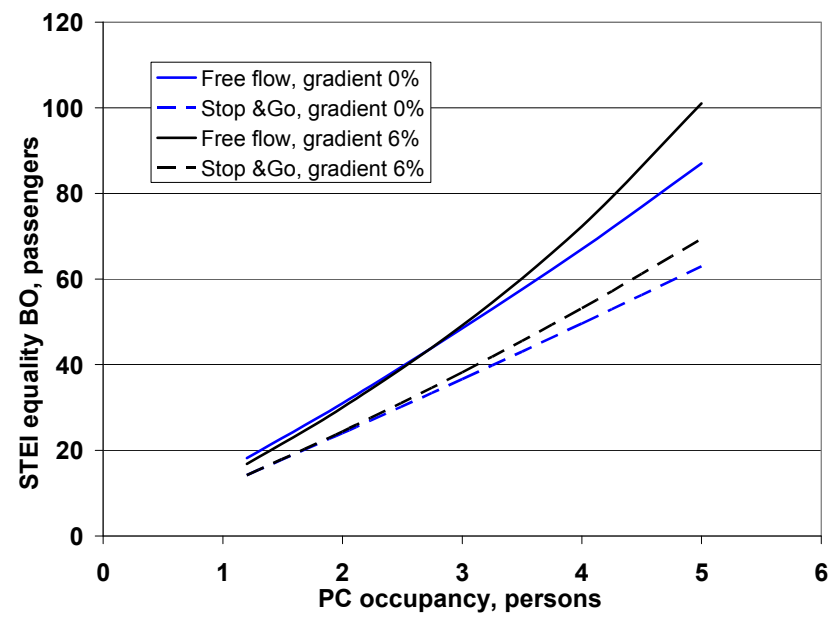

Figure 2. STEI equality $B O$ versus PC occupancy. Free flow and stop \& go levels of service, road gradients 0 and $6 \%$, urban access road

Calculation results show that the influence of road gradient on the bus occupancy level providing equality of the bus STEI with that of PC is quite weak (few percent). However, it becomes sensible at road gradients exceeding $4 \%$ and PC occupancy values above 3 persons per vehicle. It is quite remarkable that for a high PC occupancy a reverse trend is observed, namely STEI equality $B O$ grows with an increasing road gradient by up to $16 \%$. In other words, as expressed in terms of STEI equality BO, at high PC occupancies the increasing road steepness is a factor less environmentally disadvantageous for PCs. These tendencies prevail for the free flow traffic and become weaker with increasing traffic congestion. The latter observation is explained by very low engine loads at "stop \& go" level of service and a dominant influence of transient regimes on emissions formation, rather than load increase due to road gradient raise.

Figure 3 shows a comparison of the STEI equality $B O$ for various road types and PC occupancy of 1.2 persons.As was already mentioned, the dependence of the STEI equality $B O$ on the road gradient is quite weak and almost unaffected by the road type. No differences were observed between STEI equality $B O$ values for various road types at stop \& go level of service. This is because of a very weak dependence of the average speed on the speed limit in the congested traffic conditions (Table 4). There are also no significant differences between the average speeds of buses and a PCs in the "stop \& go" traffic for both studied road types.

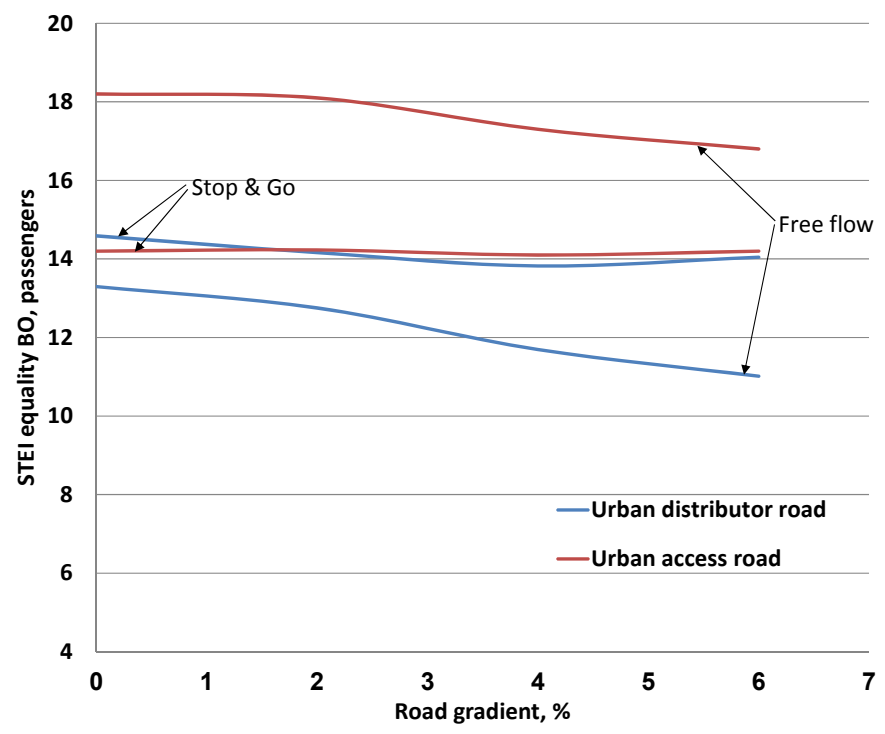

Figure 3. Comparison of STEI equality BO for different road types, PC occupancy-1.2 persons 
Table 4. Average speeds of buses and PCs at different road types and levels of service

\begin{tabular}{lllll}
\hline Level of service & \multicolumn{2}{c}{ Free flow } & \multicolumn{2}{c}{ Stop \& Go } \\
\hline Road type & Access road & Distributor road & Access road & Distributor road \\
\hline Speed limit, $\mathrm{km} / \mathrm{h}$ & 50 & 80 & 50 & 80 \\
Urban bus & 25.7 & 53.7 & 11.8 & 13.5 \\
Passenger car & 45.8 & 70.1 & 12.7 & 16 \\
\hline
\end{tabular}

The data shown in Table 4 suggest that at free flow traffic conditions the average PC speed is close to the speed limit at both road types. The average bus speed at free flow traffic conditions is about $50 \%$ of the speed limit at urban access road and increases up to $67 \%$ of the speed limit at urban distributor road. The average bus speed at the urban distributor road is closer to the speed limit, thus indicating that a number of bus acceleration/deceleration events is reduced compared with a free flow driving at the urban access road. Normally this stems from a reduction in the number of bus stops per $\mathrm{km}$. The number of transient events for buses is lower on urban distributor roads than on access roads and this explains the concomitantly lower vehicle emissions and fuel consumption. The PC average speed is close to the speed limit for both road types and this explains why the bus becomes environmentally and energetically beneficial over the PC at lower occupancy values if it is driven on a distributor road with higher average speed compared to the access road. The results shown in Figure 3 support this explanation.

\subsection{Comparison of Energy Impacts}

Figure 4 shows the $S F C$ equality $B O$ calculated for the various PC occupancies at road gradients 0 and $6 \%$ and urban access road. The data presented in Figure 4 show that buses become to be energetically beneficial with respect to the passenger cars at bus occupancies substantially lower compared with those providing the STEI equality. For example, at typical PC occupancy of 1.2 and a flat road SFC equality is achieved at a bus occupancy of 7 and 4.8 passengers per bus (for free flow and stop \& go conditions, respectively) compared with 18 and 14 passengers required to achieve the STEI equality. The reported trend is attributed to the PCs fleet composition, which almost entirely consists of cars with spark ignition (SI) engines (Table 3) as opposed to buses equipped by diesel engines. It is known that diesel engines are featured by better efficiency together with comparable or even worse pollutant emissions compared to SI engines. Therefore, if the share of diesel cars in the PC fleet is significant (a situation typical for many European countries), higher bus occupancy values will be required to achieve the SFC equality. On the other hand, this PC fleet change will lead to a reduction of bus occupancy values yielding the environmental impact equality.

The tendency of changing $S F C$ equality $B O$ values as a function of $P C$ occupancy and level of service is similar to that one described earlier for STEI equality BO. For a given PC occupancy, a reduction of bus fuel consumption with less congested traffic is lower compared with that of passenger cars. As was noted earlier, this is mainly the result of a different contribution of throttling losses to bus and PC fuel consumption. 


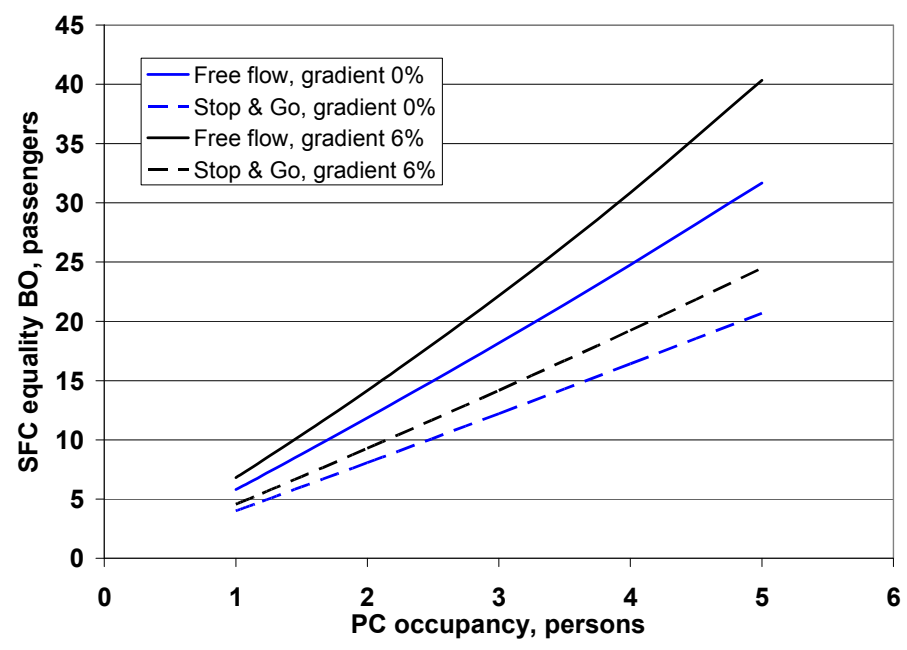

Figure 4. Dependence of SFC equality BO on PC occupancy. Free flow and stop \& go levels of service, road gradients 0 and $6 \%$, urban access road

Figures 5, 6 show the influence of the road gradient on $S F C$ equality $B O$ for the urban access road and the different PC occupancies at free flow and stop \& go levels of service, respectively. In contrast to the conclusions drawn for emissions comparison, the road gradient effect on $S F C$ equality $B O$ does not change its character depending on PC occupancy. For all studied occupancy values the $S F C$ equality $B O$ increases (up to $25 \%$ ) with the road gradient growth. The dependence of $S F C$ equality $B O$ on road gradient becomes weaker at lower PC occupancies and more congested traffic. These results show that the fuel consumption of buses rises with increase of the road gradient or vehicle occupancy more sharply than that of PCs. The observed effect may be a combined result of the mentioned above differences in throttling losses and differences in driving style of bus and car drivers. The former is mainly a bimodal style very roughly called "full gas-full brakes" driving (Tartakovsky et al., 2003) and aimed at keeping a constant driving speed. The latter is aimed at the achievement of the best possible fuel economy. As a result, at steep road or high occupancies the bus fuel consumption increases at a higher extent compared to that of a PC. This hypothesis is supported by the results obtained for the "stop \& go" level of service. The very low traffic speeds in the latter case quite limit the realization of a bimodal bus driving style, thus leading to a reduction of differences in the fuel consumption change as a function of the road gradient or vehicle occupancy. It should be noted that the applied ARTEMIS model is based on measured driving cycles, thus the differences in the driving style are reflected in the modeling results.

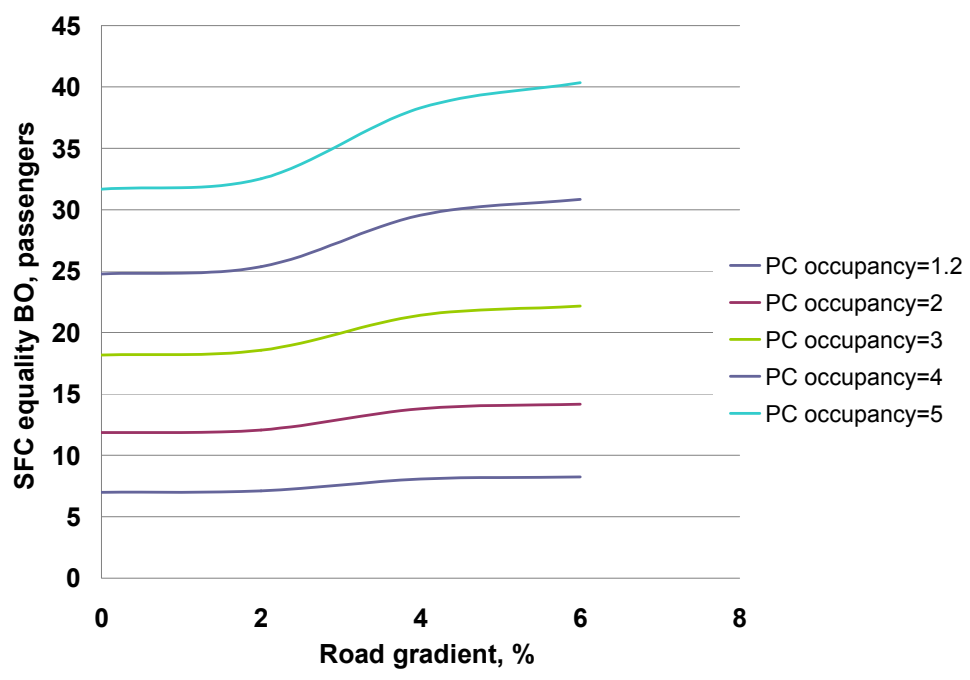

Figure 5. Dependence of $S F C$ equality $B O$ values on road gradient, free flow level of service, urban access road 


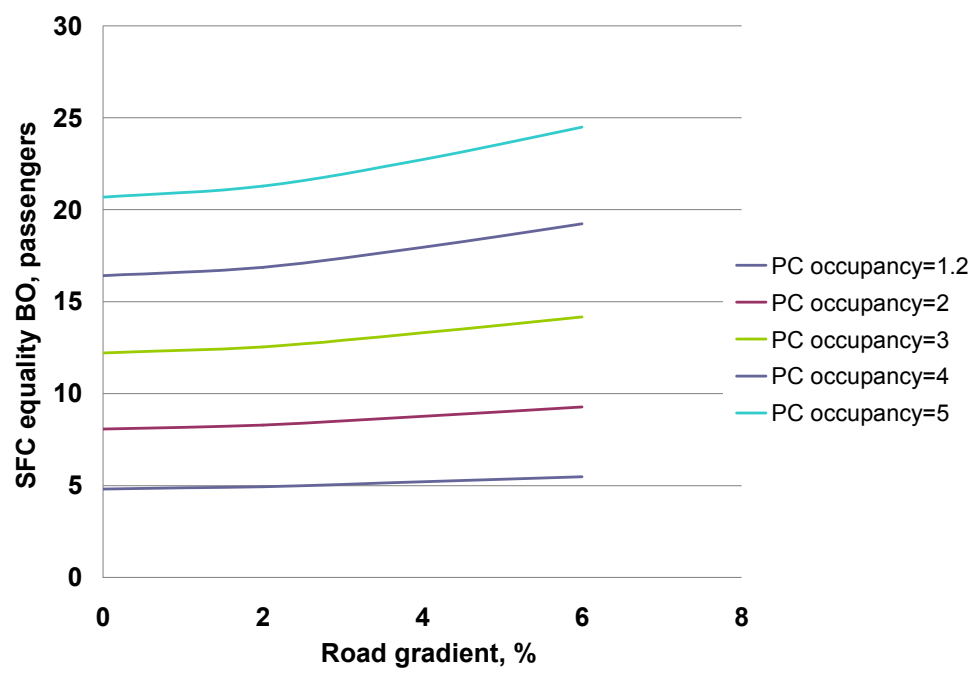

Figure 6. Dependence of $S F C$ equality $B O$ values on road gradient, stop \& go level of service, urban access road

\section{Conclusions}

A methodology is developed for a comparative analysis of energy and environmental impacts of various urban transport modes. A total emission indicator is used as a tool for integral assessment of vehicle emissions. The environmental impact factor is suggested for a comparison between transport modes using different energy sources. Vehicle occupancy values, yielding equality of the specific environmental impact factors and specific energy consumption of the compared transport modes are used for the analysis purposes.

The developed methodology takes into account both the emissions level and the number of people exposed to the polluted air. This allows projecting health impacts caused by air pollution from vehicles that use different energy sources.

The methodology is applied for a comparison between buses and passenger cars at various levels of service, road gradients and urban road types. The results of the comparative analysis show that for driving on urban access roads with a speed limit of $50 \mathrm{~km} / \mathrm{h}$ and PC occupancy of 1.2 persons the fleet averaged specific emissions (STEI) by urban buses become lower compared with PC, if the buses passenger load is higher than 14-18 persons. Buses become to be energetically beneficial over passenger cars at occupancy values substantially lower compared with those providing the emissions equality $-4.8-7$ persons depending on the level of service. This is explained by the fact that in the considered case almost the whole PC fleet has SI engines as opposed to buses equipped by more efficient diesel engines. If the share of diesel cars in the PC fleet is significant (situation typical for many European countries) higher bus occupancy values will be required to achieve the $S F C$ equality.

The influence of the road gradient on STEI equality bus occupancy is quite weak and becomes sensible at steeper roads. The tendency of the STEI equality $B O$ dependence on road gradient remains quite similar for different road types. At free flow level of service, when the average PC speed is close to the speed limit, urban buses become to be environmentally and energetically beneficial over PCs at lower occupancy values on roads with higher average speed. No significant differences were observed between STEI and SFC equality BOs for various road types at stop \& go level of service.

\section{Acknowledgements}

The research leading to these results has received funding from the European Community's Seventh Framework Program under the grant agreements 218636/Conduits and 231341/CATS. This financial support is gratefully acknowledged.

\section{References}

Ahman, M. (2001). Primary energy efficiency of alternative powertrains in vehicles. Energy, 26, 973-989. http://dx.doi.org/10.1016/S0360-5442

American Conference of Governmental Industrial Hygienists. (2010). Threshold Limit Values and Biological Exposure Indices. Cincinnati, OH: American Conference of Governmental Industrial Hygienists. 
André, M., \& Rapone, M. (2009). Analysis and modeling of the pollutant emissions from European cars regarding the driving characteristics and test cycles. Atmospheric Environment, 43(5), 986-995. http://dx.doi.org/10.1016/j.atmosenv.2008.03.013

André, M., Fantozzi, C., \& Adra, N. (2006). Development of an approach for the estimation of the road transport pollutant emissions at a street level. ARTEMIS WP1000 report LTE06, Bron: INRETS.

André, M., Keller, M., Sjödin, Å.,Gadrat, M., McCrae, I.,\& Dilara, P. (2009). The Artemis European Tools for Estimating the Transport Pollutant Emissions. Proc. 18th International Emission Inventories Conference (pp. 1-10).

Bradley, M. J., \& Associates. (2007). Comparison of energy use and $\mathrm{CO}_{2}$ emissions from different transportation modes.Report to American Bus Association, 17. Retrieved from http://www.buses.org/files/ComparativeEnergy.pdf

Curtiss, P. S., \& Rabl, A. (1996).Impacts of air pollution: general relationships and site dependence. Atmospheric Environment, 30(19), 3331-3347. http://dx.doi.org/10.1016/1352-2310

De Vlieger, I., De Keukeleere, D., \& Kretzschmar, J. G. (2000). Environmental effects of driving behavior and congestion related to passenger cars. Atmospheric Environment, 34, 4649-4655. http://dx.doi.org/10.1016/S1352-2310(00)00217-X

Dincer, I., Rosen, M., \& Zamfirescu, C. (2010). Economic and Environmental Comparison of Conventional and Alternative Vehicle Options. In G. Pistoia (Ed.), Electric and Hybrid Vehicles (pp. 1-17). Amsterdam: Elsevier.

Fox, H., \& Eweka, E. (2009). Simulation of hybrid buses: a study of fuel economy and emissions. WIT Transactions on the Built Environment, 107, 129-141. http://dx.doi.org/10.2495/UT090131

Granovskii, M., Dincer, I., \& Rosen, M. (2006). Economic and environmental comparison of conventional, hybrid, electric and hydrogen fuel cell vehicles. Journal of Power Sources, 159, 1186-1193. http://dx.doi.org/10.1016/j.jpowsour.2005.11.086

Lenaers, G., \& De Vlieger, I. (1997). On-board emission measurements on petrol-driven cars and diesel city buses. International Journal of Vehicle Design, 18(3-4), 368-378.

Nylund, N. O., Erkkilä, K., Lappi, M., \& Ikonen, M. (2004). Transitbus emissions study: comparison of emissions from diesel and natural gas buses. VTT research report PRO3/P5150/04, 63. Retrieved from http://www.vtt.fi/inf/pdf/jurelinkit/VTTNylund.pdf

Nylund, N.O., Erkkilä, K., \& Hartikka, T. (2007). Fuel consumption and exhaust emissions ofurban buses. Performance of the new diesel technology. VTT Tiedotteita, Research Notes 2373, 48. Retrieved from http://www.vtt.fi/inf/pdf/tiedotteet/2007/T2373.pdf

Parent, M. (2007). Advanced urban transport: automation is on the way. IEEE Intelligent Systems, 22(2), 9-11. http://dx.doi.org/10.1109/MIS.2007.20

Pope, C. A., \& Dockery, D. W. (2006). Health effects of fine particulate air pollution. Journal of the Air \& Waste Management Association, 56, 709-742. http://dx.doi.org/10.1080/10473289.2006.10464485

Radovic, D. (2009). Eco-Urbanity: towards well-mannered built environments. London and New York: Routledge.

Silva, C., Bravo, J., Gonçalves, G., Farias, T., \& Mendes-Lopes, J. (2007). Bus public transport energy consumption and emissions versus individual transportation. Proc. Transportation Land Use Planning and Air Quality Congress, Copyright ASCE, 147-160. http://dx.doi.org/10.1061/40960(320)15

Sram, R. J., Binkova, B., Beskid, O., Milcova, A., Rossner, P., Rossner, P. Jr., ... Topinka, J. (2011). Biomarkers of exposure and effect interpretation in human risk assessments. Air Quality Atmosphere and Health 4, 161-167. http://dx.doi.org/10.1007/s11869-011-0133-8

Tartakovsky, L., Gutman, M., \& Mosyak, A. (2012). Energy efficiency of road vehicles - trends and challenges. In E. F. S. Cavalcanti, \& M. R. Barbosa (Eds.), Energy Efficiency: Methods, Limitations and Challenges (pp. 63-90). New York: Nova Science Publishers.

Tartakovsky, L., Mosyak, A., \& Zvirin, Y. (2013). Energy analysis of ethanol steam reforming for internal combustion engine. International Journal of Energy Research, 37, 259-267. http://dx.doi.org/10.1002/er.1908 
Tartakovsky, L., Zvirin, Y., Motzkau, M., Van Poppel, M., Riemersma, I., Veinblat, M., ... Gutman, M. (2003). Measurements and analysis of real-world driving behavior of urban buses. Proc. the 12th International Scientific Symposium on Transport and Air Pollution, Avignon (France).

Tsang, K. S., Hung, W. T., \& Cheung, C. S. (2011). Emissions and fuel consumption of a Euro 4 car operating along different routes in Hong Kong. Transportation Research Part D, 16, 415-422. http://dx.doi.org/10.1016/j.trd.2011.02.004

Wang, T., Bai, J., Jiang, X., \& Nienhaus, G. U. (2012). Cellular uptake of nanoparticles by membrane penetration: a study combining confocal microscopy with FTIR spectroelectrochemistry. ACS Nano, 6(2), 1251-1259. http://dx.doi.org/10.1021/nn203892h

\section{Copyrights}

Copyright for this article is retained by the author(s), with first publication rights granted to the journal.

This is an open-access article distributed under the terms and conditions of the Creative Commons Attribution license (http://creativecommons.org/licenses/by/3.0/). 